\title{
Profile of patients with pancreatic cancer and diabetes mellitus at the University Hospital of Brazzaville
}

\author{
Rody Stéphane Ngami1,2, Evariste Bouenizabila², Arnaud Mongo-Onkouo ${ }^{1,2}$, \\ Jile Florient Mimiesse ${ }^{1,2}$, Ngala Akoa Itoua-Ngaporo',2, Motoula Latou Pérès Mardochée1,2, \\ Relda Itoko Okombi ${ }^{1}$, Philestine Clausina Mikolele Ahoui Apendi ${ }^{1,2}$, Deby Gassaye ${ }^{1,2}$, \\ Blaise Irénée Atipo Ibara',2, Jean-Rosaire Ibara ${ }^{1,2}$ \\ ${ }^{1}$ Department of Gastroenterology and Internal Medicine, Brazzaville University Hospital, Brazzaville, Republic of the Congo \\ ${ }^{2}$ Faculty of Health Sciences, Marien Ngouabi University, Brazzaville, Republic of the Congo \\ Email: rodyngami@gmail.com
}

How to cite this paper: Ngami, R.S., Bouenizabila, E., Mongo-Onkouo, A., Mimiesse, J.F., Itoua-Ngaporo, N.A., Mardochée, M.L.P., Okombi, R.I., Apendi, P.C.M.A., Gassaye, D., Ibara, B.I.A. and Ibara, J.-R. (2021) Profile of patients with pancreatic cancer and diabetes mellitus at the University Hospital of Brazzaville. Open Journal of Gastroenterology, 11, 105-111.

https://doi.org/10.4236/ojgas.2021.116011

Received: April 27, 2021

Accepted: June 27, 2021

Published: June 30, 2021

Copyright () 2021 by author(s) and Scientific Research Publishing Inc. This work is licensed under the Creative Commons Attribution International License (CC BY 4.0).

http://creativecommons.org/licenses/by/4.0/

(c) (i) Open Access

\begin{abstract}
Introduction: pancreatic cancer a poor prognosis disease for which there is no screening. Its association with diabetes is not uncommon and may influence the evolutionary profile. The aim of this study was to describe the profile of diabetic patients who could benefit from pancreatic cancer screening. Methods: we conducted a retrospective cross-sectional study in the gastroenterology department of the University Hospital of Brazzaville, from January 2010 to December 2019. Epidemiological variables (age, sex, alcoholism, smoking), tumor variables (symptoms, site, size, density, extension) and time of occurrence of both entities were analyzed using Epi info software. Results: A total of 35 patients were hospitalized for pancreatic cancer, of whom 17 were men and 15 women, for a sex ratio of 1.21 . The mean age of the patients was $60.3 \pm 13$ years. Fifteen patients (43.75\%) were diabetic, all classified as type 2 . Among them, the diagnosis of diabetes of $10 \mathrm{pa}-$ tients $(66.7 \%)$ preceded pancreatic cancer diagnosis and delay between the two pathologies was on average 3.4 years \pm 5.3 months. Diabetes was observed in 11 patients older than 60 years. The difference was significant $(\mathrm{OR}=4.8 ; 95 \% \mathrm{CI}$ [1.1 - 22.8]; $\mathrm{p}=0.0226)$. The other epidemiological variables studied were not related to the two pathologies. Conclusion: we propose a screening for pancreatic cancer when diabetes is discovered to patients from 60 years old, whatever their sex, especially during the first 3 years after the discovery of diabetes.
\end{abstract}

Keywords 
Pancreatic Cancer, Diabetes Mellitus, Association

\section{Introduction}

Pancreatic cancer is the third leading cause of cancer death worldwide [1]. Despite its seriousness, there is no existing screening programme for this cancer which generally has a poor prognosis. Diabetes mellitus, a major health problem affecting more than $7 \%$ of the world's population, is a risk factor for certain cancers, including pancreatic and liver cancer [2]-[7]. The lack of an early detection programme for pancreatic cancer probably explains its high mortality rate [8] [9] [10] [11] as its management is difficult [2] [3] [5]. Some authors have clearly shown an increase in the prevalence of cancers such as pancreatic cancer with diabetes [12] [13] [14]. The research hypothesis was that diabetes could be predictive of existing of pancreatic cancer. To help improve the early detection of pancreatic cancer, we analysed the characteristics of pancreatic cancer associated with diabetes mellitus. The objectives of this study were to determine the prevalence of diabetes in pancreatic cancer, to determine the risk factors associated with diabetes in pancreatic cancer and to analyse the characteristics of diabetics with pancreatic cancer.

\section{Patients and Methods}

We conducted a retrospective cross-sectional analytical study in the hepato-gastroenterology department of the CHUB from January 2010 to December 2019 , a period of 10 years. We included all cases of pancreatic cancer regardless of age and gender. The diagnosis of pancreatic cancer was evoked clinically and confirmed by abdominal ultrasound or CT or MRI scan showing a solid tumour of the pancreas enhancing after contrast injection on CT or MRI. Histological evidence was not required for a diagnosis of pancreatic cancer. Non-solid tumours (cysts and pseudocysts) of the pancreas were excluded from this study. The diagnosis of diabetes mellitus was made on the basis of blood glucose and glycated haemoglobin values. Diabetes was confirmed when the blood glucose level was above $1.26 \mathrm{~g} / \mathrm{l}$ and/or the glycated haemoglobin level was above $6.5 \%$. We performed a non-probability sampling by systematically recruiting all cases meeting the inclusion criteria. The variables studied were epidemiological such as age, sex, alcohol and tobacco consumption; diabetes characteristics such as family history of diabetes, type, duration of diabetes, antidiabetic treatment administered and tumour characteristics such as symptoms, tumour site, size, tumour density on imaging, presence of metastases. The endpoints were the association between pancreatic cancer and diabetes mellitus, the diagnostic chronology of the two diseases and the diagnostic delay between diabetes and pancreatic cancer. Data were processed using Epi Info 7.2 software. The significance level for statistical tests was set at 0.05 . Based on these criteria, 35 patients were included in the study. 


\section{Results}

During our period study, we collected 958 cases of cancer diagnosed in the department, including 35 cases of pancreatic cancer, representing 3.6\% of cancer hospitalizations.

Among the 35 cases of pancreatic cancer, there were 19 (54.3\%) men and 16 (43.7\%) women, a sex ratio of 1.2. The mean age was $60.3 \pm 13$ years, the young age were 23 years and the old one were 90 years. Figure 1 showed the distribution of patients in age groups. Alcohol and tobacco intake were observed in 21 $(88.6 \%)$ and $8(22.9 \%)$ cases. Jaundice was the main reason for hospitalization. Table 1 showed the distribution of patients according to the reasons for consultation. Abdominal ultrasound was the most common imaging test performed. It was performed in 32 cases (91.4\%), followed by abdominal CT in 23 cases (65.7\%) and pancreatic MRI in 1 case (2.9\%). Abdominal ultrasound was coupled with abdominal CT in 19 cases (54.3\%). Pancreatic cancer was cephalic site in 28 cases, or $80 \%$, corporal in 6 cases, or $17.1 \%$, and tail in 1 case, or $2.9 \%$. There was no statistically significant difference between tumor site and association with diabetes mellitus $(\mathrm{OR}=1.4 ; 95 \% \mathrm{CI}[0.2-8.2] ; \mathrm{p}=0.3596)$. The mean size of the pancreatic tumors was $45.6 \mathrm{~mm} \pm 15$, the extremes were 12 and 89 $\mathrm{mm}$. Tumor density was variable, increased in 2 cases $(5.7 \%)$, decreased in 25 cases $(71.4 \%)$ and heterogeneous in 8 cases $(22.9 \%)$. A hypodense image of pancreatic cephalic cancer seen in one patient was shown on Figure 2. In 26 patients (74.3\%), there were no distant metastases, whereas 9 patients (25.7\%) had

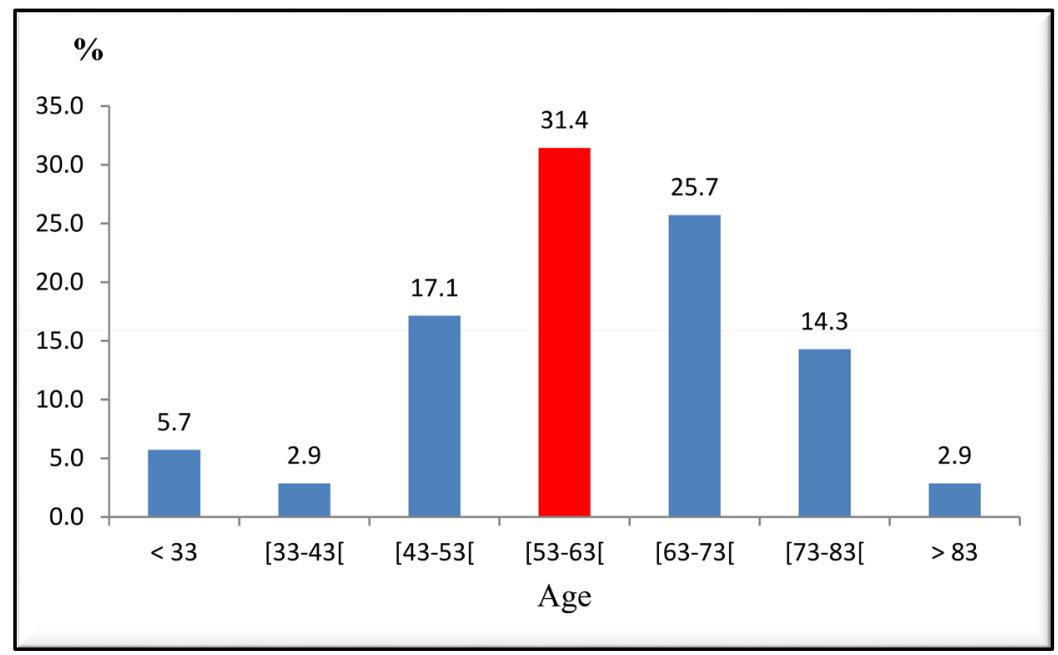

Figure 1. Age distribution of patients.

Table 1. Clinical manifestations of pancreatic cancer.

\begin{tabular}{ccc}
\hline \multirow{2}{*}{ Clinical Manifestations } & \multicolumn{2}{c}{$\mathbf{N}=\mathbf{3 5}$} \\
\cline { 2 - 3 } & $\mathbf{n}$ & $\%$ \\
\hline Jaundice & 27 & 77,1 \\
Abdominal pain & 19 & 54,3 \\
\hline
\end{tabular}




\begin{tabular}{ccc}
\hline Altered general condition & 13 & 37,1 \\
Vomiting & 2 & 5,7 \\
\hline
\end{tabular}

metastases. Among the 35 patients, $9 \%$ or $25.7 \%$ had a family history of diabetes mellitus while and $26(74.3 \%)$ had no history of it, fifteen patients (42.9\%) were diabetic, 6 of whom had a family history of diabetes mellitus. All people with diabetes were type 2 and they were treated differently: 7 patients (46.7\%) were treated with insulin, 3 (20\%) with a hypoglycemic diet alone, 3 (20\%) with oral antidiabetic drugs (OADs) and $2(13.3 \%)$ with a combination of insulin and OADs. The average duration of diabetes was 34.83 months with extremes of 1 month and 12.17 years. The diagnosis of pancreatic cancer and diabetes mellitus was synchronous in 5 cases (33.3\%) whereas in 10 cases (66.7\%) the diagnosis of diabetes preceded that of pancreatic cancer. For the 10 in whom diabetes was discovered before pancreatic cancer, the mean duration of diabetes was 3.4 years \pm 5.3 months before pancreatic cancer discovering; the extremes were 1 month and 6.1 years. Table 2 represented the relationship between epidemiological

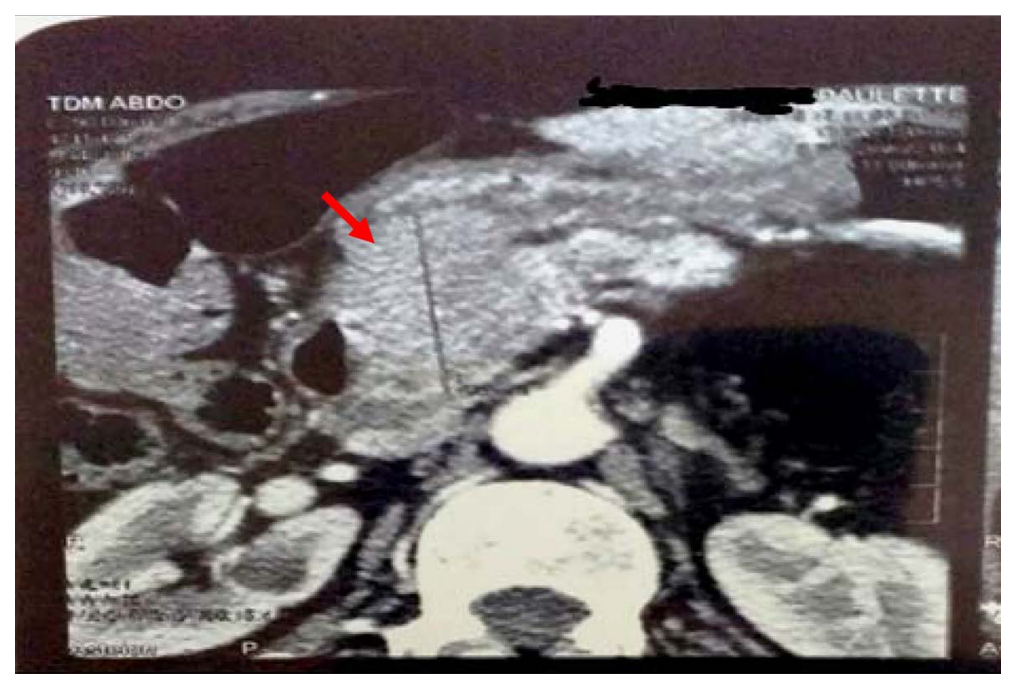

Figure 2. Hypodense picture of pancreas' head (red arrow) on CT scan.

Table 2. Relationship between epidemiological factors and presence of diabetes.

\begin{tabular}{|c|c|c|c|c|c|c|}
\hline & & \multicolumn{2}{|c|}{ diabetes mellitus } & \multirow{2}{*}{ OR } & \multirow{2}{*}{ IC $95 \%$} & \multirow{2}{*}{$\mathrm{p}$} \\
\hline & & Yes (\%) & No (\%) & & & \\
\hline \multirow[b]{2}{*}{ Age } & $<60$ years old & $3(20)$ & 11 & \multirow{2}{*}{4.8} & \multirow[b]{2}{*}[1.1-22.8]{} & \multirow[b]{2}{*}{0.0226} \\
\hline & $\geq 60$ years old & 12 & 9 & & & \\
\hline \multirow{2}{*}{ Sex } & Female & $7(46.7)$ & $9(45)$ & \multirow{2}{*}{1.1} & \multirow{2}{*}[0.2-4.1]{} & \multirow{2}{*}{0.4627} \\
\hline & Male & $8(53.3)$ & $11(55)$ & & & \\
\hline \multirow{2}{*}{$\begin{array}{c}\text { Family history } \\
\text { diabetes }\end{array}$} & Yes & $6(40)$ & $3(15)$ & \multirow{2}{*}{3.7} & \multirow{2}{*}[0.7-18.8]{} & \multirow{2}{*}{0.0596} \\
\hline & No & $9(60)$ & $17(85)$ & & & \\
\hline \multirow{2}{*}{ Alcohol } & Yes & $9(60)$ & $12(60)$ & \multirow{2}{*}{1} & \multirow{2}{*}[0.3-3.9]{} & \multirow{2}{*}{0.4829} \\
\hline & No & $6(40)$ & $8(40)$ & & & \\
\hline
\end{tabular}




\begin{tabular}{|c|c|c|c|c|c|c|}
\hline \multirow{2}{*}{ Tobacco } & Yes & $3(20)$ & $5(25)$ & \multirow{2}{*}{0.7} & \multirow{2}{*}{$0.1-3.7$} & \multirow{2}{*}{0.3775} \\
\hline & No & $12(80)$ & $15(75)$ & & & \\
\hline
\end{tabular}

variables, diabetes variables and pancreatic cancer. Age over 60 years was statistically associated with the presence of both diseases (OR $=4.8 ; 95 \%$ CI $[1.1$ 22.8]; $\mathrm{p}=0.0226)$. Variables as sex, tobacco, alcohol and family history diabetes was not associated with diabetes and pancreatic cancer.

\section{Discussion}

Diagnosis of pancreatic cancer is often late sometimes difficult due to limited investigation exams in our country. That may explain the low of our sample size. In addition, the retrospective nature of our study may be a source of selection error. The sample size and the retrospective nature are probably limitations of this study But results obtained over 10-years period can be representative of the population. Pancreatic cancer remains a disease of elderly subjects in many studies [8] [9] [10], whereas diabetes, especially type 2, is discovered around 40 years of age [4] [5]. Some authors [2] [3] have reported an association between the discovery of diabetes beyond the age of 50 years and pancreatic diseases such as chronic pancreatitis or pancreatic cancer. In our study, from 60 years old onwards was a factor statistically related to the association diabetes mellitus and pancreatic cancer. Thus, age could be a major factor in the detection of pancreatic cancer in diabetics persons. Concerning gender, many authors [8] [9] [10] [11] have found a male predominance in pancreatic cancer. That is probably explained by the high consumption of alcohol and tobacco in men, although this trend is tending to be reversed. Sellem et al. in Algeria [8] and Ouattara et al. in Burkina Faso [9] reported alcohol and tobacco consumption of $20.6 \%$ and $32.5 \%$ and $46.8 \%$ and $59.4 \%$ respectively in male patients. However, tobacco consumption is more a risk factor for pancreatic cancer, alcohol consumption is a risk factor for chronic pancreatitis [1]. We did not find an association between these two risk factors and diabetes during pancreatic cancers. The pancreatic cancers localisations are cephalic extremity in more $80 \%$ of cases [8] [9], explaining the symptoms found in our study, dominated by jaundice. Jaundice is a symptom that most often motivates an immediate hospital consultation but it also reflects an already advanced form of pancreatic cancer, corroborating that pancreatic cancer is often of late diagnosis [9] [10] [12]. Therefore, the search for jaundice should not be an early diagnostic feature of pancreatic cancers. The frequency of metastasis at the time of diagnosis is variable according to some authors, 26.2\% in Algeria [7] and $90.6 \%$ in Burundi [11], proof that it is a cancer with a poor prognosis. In the literature, the association between diabetes mellitus and pancreatic cancer is mentioned by some authors [2] [3] [6] [7] [13] even if controversies remain. For Ouattara in Ivory Coast [9] and Kouhen in Morocco [12], diabetes mellitus was associated with pancreatic cancer in $20.7 \%$ and $44.6 \%$ respectively. In this context, the delay between the two diseases was considered as a risk factor for the occurrence of pancreatic cancer. For Kouhen in Morocco 
[12], in $64 \%$ of cases, this delay was less than 2 years. On the other hand, other authors [13] [14] [15] [16] [17] estimate the risk of diagnosing pancreatic cancer was multiplied by 3 or 6 in the first year after the discovery of diabetes. This risk was reduced to around 1.3 when the discovery of diabetes was more than 10 years ago [15] [17]. For Prizment et al. [3], the duration of diabetes does not seem to increase the risk of pancreatic cancer, although this risk persists. In all cases, a risk of an association between diabetes mellitus and pancreatic cancer is described. In our study we cannot compare the duration of diabetes and the occurrence of pancreatic cancer with a control group, hence the interest in conducting a comparative prospective study at a later date in which the same epidemiological variables will be studied.

\section{Conclusion}

Our study confirms the association between pancreatic cancer and diabetes mellitus. The discovery of diabetes in patients aged 60 years and older was statistically related to the presence of pancreatic cancer, the mean time to diagnosis of pancreatic cancer was 3 years. Screening for pancreatic cancer can therefore be proposed by cross-sectional imaging combining abdominal ultrasound and injected abdominal CT when diabetes mellitus is discovered from 60 years old. The pace of screening will be able to specify by a prospective follow-up of diabetic patients which will be carried out in the near future to better evaluate the association between diabetes and pancreatic cancer.

\section{Conflicts of Interest}

The authors declare no conflicts of interest regarding the publication of this paper.

\section{References}

[1] Lefèvre, J., Galbois, A., Rudler, M., et al. (2017) Medical and Surgical Hepato-Gastroenterology: Pancreatic Cancer. Vernazobre-Grégo, Paris, 195-214.

[2] Gariani, K., Tran, C. and Philippe, J. (2010) Diabetes and Cancer: An Injurious Association. Revue Médicale Suisse, 6, 1193-1194, 1196-1198.

[3] Henry, S.A., Prizment, A. and Anderson, K. (2014) Duration of Diabetes and Pancreatic Cancer in a Case-Control Study in the Midwest and the Iowa Womens' Health Study (IWHS) Cohort. Journal of the Pancreas, 14, 243-249.

[4] World Health Organization (year) Global Diabetes Report 2018.

[5] Scheen, A., Radermecker, R., Philips, J.C., et al. (2013) European Recommendations for the Management of Diabetes and Cardiovascular Disease. Management of Diabetes and Cardiovascular Risk Factors. Liege Medical Journal, 68, 585-592.

[6] Paepegaey, A.C. and Fève, B. (2016) Diabetes Associated with Pancreatic Cancer Is Paraneoplastic Diabetes. Medicine of Metabolic Diseases, 10, 238-342. https://doi.org/10.1016/S1957-2557(16)30056-6

[7] Simon, D. (2009) Diabetes and cancer. Medicine of Metabolic Diseases, 3, 320-327. https://doi.org/10.1016/S1957-2557(09)74762-5 
[8] Sellem, F., Harir, N., Khaled, M.B., Mrabent, M.N., Salah, R., Diaf, M., et al. (2015) Epidemiological and Histopronostic Aspects of Pancreatic Cancer at the Level of Western Algeria Proposing 160 Cases. Jour Afr d'Hépato-Gastroentérologie, 9, 76-79. https://doi.org/10.1007/s12157-015-0592-x

[9] Ouattara, A., Kone, S., Soro, D., Assi, C., Allah-Kouadio, E., Bi, R., et al. (2017) Pancreatic Cancer: Epidemiological, Clinical and Therapeutic Aspects in Abidjan. Open Journal of Gastroenterology, 7, 223-229.

[10] Bambara, A.T., Zida, M., Ouangré, E., Bambara, A.H., Zongo, N. and Traoré, S.S. (2014) Pancreatic Head Tumor: A Diagnostic and Therapeutic Challenge in Ouagadougou. Journal Africain du Cancer, 6, 17-21. https://doi.org/10.1007/s12558-013-0291-8

[11] Ntagirabiri, R., Niyonkuru, S., Karayuba, R., Ndayisaba, G. and Marerwa, G. (2012) Pancreatic Cancer in Bururndi Experience of Kamenge University Hospital. Journal Africain d Hépato-Gastroentérologie, 6, 312-314. https://doi.org/10.1007/s12157-012-0422-3

[12] Kouhen, F. (2011) Pancreatic Cancer and Diabetes about 56 Cases. Thesis of Medicine, Mohammed V University, Rabat. http://ao.um5s.ac.ma/xmlui/handle/123456789/425

[13] Wideroff, L., Gridley, G., Chow, W.-H., Linet, M., Mellemkjaer, L., Olsen, J.H., et al. (1999) Cancer Incidence in a Population-Based Cohort of Patients Hospitalized with Diabetes Mellitus in Denmark. Journal of the National Cancer Institute, 89, 1360-1365. https://doi.org/10.1093/jnci/89.18.1360

[14] Batabyal, P., Vander Hoorn, S., Christophi, C. and Nikfarjam, M. (2014) Association of Diabetes Mellitus and Pancreatic Adenocarcinoma: A Meta-Analysis of 88 Studies. Annals of Surgical Oncology, 21, 2453-2462.

https://doi.org/10.1245/s10434-014-3625-6

[15] Dankner, R., Boffetta, P., Balicer, R.D., Keinan Boker, L., Sadeh, M., Berlin, A., et al. (2016) Time-Dependent Risk of Cancer after a Diabetes Diagnosis in a Cohort of 2.3 Million Adults. American Journal of Epidemiology, 183, 1098-1106. https://doi.org/10.1093/aje/kwv290

[16] Song, S., Wang, B., Zhang, X., Hao, L., Hu, X., Li, Z., et al. (2015) Diabetes Mellitus Is Associated with an Increased Risk of Pancreatic Cancer: A Meta-Analysis. PLoS ONE, 10, e0134321. https://doi.org/10.1371/journal.pone.0134321 https://journals.plos.org/plosone/article?id=10.1371/journal.pone.0134321

[17] De Bruijn, K.M.J., Ruiter, R., De Keyse, C.E., Hofman, A., Stricker, B.H. and van Eijck, C.H.J. (2014) Detection Bias May Be the Main Cause of Increased Cancer Incidence among Diabetics Results from the Rotterdam Study. European Journal of Cancer, 50, 2449-2455. https://doi.org/10.1016/j.ejca.2014.06.019 